\title{
Use of Open Data in the Development of the Digital Economy in the Knowledge Society in the Era of Globalization
}

\author{
Katarina Repkova Stofkova ${ }^{1}$, Jana Stofkova ${ }^{1, *}$ \\ ${ }^{1}$ University of Zilina, Faculty of Operation and Economics of Transport and Communication, 01026 \\ Zilina, Slovakia
}

\begin{abstract}
Process of electronization is one of the milestones in the development of technological processes that leads to an improvement in the quality of life of citizens. The process of electronization is taking place all over the world. From the world leaders in the field of digitization of processes and data it is necessary to solve many things in the Slovak Republic, the development is in the right direction. The concept of national disclosure and delivery of important information is being addressed. The implementation of new information communication technologies and the introduction of processes have improved the awareness of citizens and businesses. By introducing open data into datasets, it also helps businesses to perform their activities more effectively. Open data contains nonpersonal data that is accessible to all and can be freely used, reused and distributed by everyone. This means that a certain type of data is available to everyone, in order to use and publish it at their own discretion, without restricting copyright, patents, or other control mechanisms. Improving aspects include raising awareness among citizens and businesses, improving the content of institutions providing such data, and so on. As part of the International Digital Economy and Society International Study, as well as the National Digital Economy and Society Index, a number of researches have been carried out that describe information and digitization. The paper lists the results of the survey focused on the ongoing development of the digital services.
\end{abstract}

\section{Introduction}

The nineties of the last century marked a significant development of information and communication technologies, also in connection with the development of the Internet. New web pages, browsers were created and gradually the creation of the web sites itself has grown from a static page (web application) to an interactive (dynamic page). This kind of modern technology began to offer a huge amount of data, information. Nowadays, extensive use of the Internet, computers and other electronic devices has penetrated the economy. Such a digital economy accounts for $6 \%$ of Slovakia's GDP, with huge room for growth. A prosperous digital economy is one of the mainstays of growth and employment.

*Corresponding author: jana.stofkova@fpedas.uniza.sk 
This economy encourages the creation of innovative online services at competitive prices and makes it easier for businesses, especially SMEs, to access cross-border markets. The digital market is reviving the growth of many sectors, with enormous job creation potential in a rapidly evolving and changing environment. Over time, this information was so extensive that data databases were created. These databases typically owned by state and public administration and part of businesses entities. As these data from the database were used by the state or by the business to carry out their activities, some data had to be protected. The paper deals with technological, information and digitalization processes that have influenced the functioning of the company in recent years. For the purpose of better access to information, the European Union project Europe 2020 has also been set up. Data make available to citizens and businesses almost all over the world.

The development of the information society and the new economy play an important role in the national economy. The rapid development of electronic communications and the subsequent liberalization of the market in this sector brought a new perspective on the development and direction of society. Electronic communications nowadays play an irreplaceable role in many spheres of life, whether in the private or public sectors. Electronic communications are playing an irreplaceable role by enabling them to meet the goals of the modern information society, the goals of which were set by the Lisbon Strategy, where building an increased competitiveness of countries based on the so-called digital.

In recent years, information and communication technologies have developed more rapidly and are now entering the mass market in the information society and media, which is only possible thanks to faster and more accessible communication links between different devices. Traditional content is currently available in digital format and new services are emerging that are digital from the beginning, such as interactive software. Digital convergence of information society and media services, networks and devices is finally becoming an everyday reality.

\section{Methods and background of the issue}

The most popular interactive medium of the present, Internet, has expanded the perception and character of the economy as a whole. The use of this network has marked all those who have begun to perceive its innumerable possibilities and benefits. With its development, there is also an enormous increase in technology which supports electronic processes, in particular e-commerce and all forms that are inherently associated with it. [1]

The digital economy is an economy based on the wide use of ICT in terms of publication of the information, communication, and purchasing and production of hardware and software. It should be pointed out that the digital economy now plays a big role, and its importance will grow with the entering in the production age generations not imagining a world without the Internet.

\subsection{Information and communication technologies and digital economy}

The aim of implementing digitalisation in the economic sphere is not an end in itself, but is intended to promote competitiveness. [2] This situation requires acquiring digital skills. [3]

Undoubtedly, the digital economy is a concept not fully defined (with blurred boundaries), highly dynamic, the multifaceted being, and consequences far beyond the same e-economy.

Measurement of digital economy until now had many complex measures, which, to a greater or lesser degree, reflect the status and dynamics. For example these indexes are used 
to measure digital economy. KEI (Knowledge Economy Index) used by World Economic Forum, first published in 2005 covered 140 countries and contained 20 partial indicators. [4]

The European Commission (EC) regards ongoing comprehensive digitalization, new innovative economic models, so called digital economy as "the power to transform human societies and economies, with long-term benefits for both the economic growth and quality of life".

The composite Digital Economy and Society Index (DESI) is calculated since 2014 as an annual analytical and benchmarking tool that "summarizes relevant indicators on Europe's digital performance and tracks the evolution of EU Member States in digital competitiveness". [5]

Increasing part of economic and business processes currently is driven by digital technologies. Competitive environment, economic and economic crisis but also political situation largely affects the business climate. In order to retain customers and achieve the maximum profit enterprises are pushed to implementation of innovative processes in their production. [6]

The process of meeting customer's needs is carried out through processes performed in a business, and at the same time the product must comply with legislative requirements. [7]

Thus, information society, with the help of ICT, improves the social situation of each individual and intervenes in business, private, and public-administrative spheres. A special branch of administrative science has developed through the increasing role of technology in the public sector, i.e. e-government. [8]

\subsection{Data and open data}

We define data as a set of disordered facts or details from which information could be derived. Individual data is useless in itself until it is processed. After the process of organization, structuring and putting it into a certain context, the individual data becomes information. Open data has three basic attributes: [9]

- Accessibility and access: data must be available as a whole, their reproduction costs should be reasonable, so the ideal solution is to publish them on the Internet.

- Re-use and redistribution: data must be provided under certain conditions that allow reuse, reallocation and addition of data to existing ones.

- Universal participation: everyone must be able to use and re-distribute this data, there must be no discrimination in the effort, whether against persons or groups. [10]

The term "open data" usually refers to non-personal data that is accessible to all and can be freely used, reused and distributed by everyone. A certain type of data is accessible to all, for use and publication at its own discretion, without limitation of copyright, patents or other control mechanisms. Data were-use by releasing data on a specific device and in a readable format, under a license that usually allows both commercial and non-commercial use. In principle, open data is based on the principle of disseminating data and reusing or reconstructing original information. Most of these data are derived from government or private sector statistics. There are several widely used definitions for open data. For example, "Open data is data that anyone can freely use, reuse, and redistribute - only if assignment and sharing is at most required.", or "Public data is objective, factual, non personal data on the management and administration of public services, which are based on political decisions, or which are collected or generated in the course of the provision of public services". [11]

Open information can be found in the fields of transport, science, products, education, sustainability, maps, legislation, libraries, economics, culture, development, trade, design, finance. The principle of openness within the concept of open data applies to all the above- 
mentioned types of information sources. Open can also apply to data such as large data and small data, or content such as images, text and music.

Such a diversity of information can help not only ordinary people but also companies and organizations to understand the needs of your potential and regular customers. [11]

As far as data generated from public sources are concerned, they should be free for all so that they can reuse them. Data are considered therefore as a common source. Data must be licensed under a license that recognizes the right of the user to use the data in a variety of ways, including commercial ones. [11, 12]

The unsecured information may cause irretrievable loss and broke the confidence of an organization or a state. The state is responsible for the security of national wealth including the knowledge and information, hence there is no reason to lower the criterion of security level. [13]

The elements related to open data in the Slovak Republic are defined by the following two sources:

- Act no. 211/2000 Coll. on free access to information and amending certain acts (Freedom of Information Act),

- Decree of the Ministry of Finance no. 55/2014 Coll. on standards for public administration information systems.

\subsection{Informatisation of public administration}

States try to achieve a variety of transformative initiative changes through eGovernment programs. The transformation was of course, facilitated and accelerated by the growth of technology. The transformation of government and public administration is in fact the result of the development of information and communication technologies. In this way, governments in every state would allow for better circulation of information, better information, more efficient processing of information, and many others. The computerization process could therefore was carried out on basis of the electronization of public administration. [14]

In the literature, we come across different definitions of the term e-Government. According to the UNO, "e-Government is a permanent duty of public administration to improve the relationship between citizens and the public sector by providing cheap and efficient services, information and knowledge. A practical implementation of what public administration can provide." [15]

E-Government use of information and communication technologies, together with organizational change and new knowledge, brings better, faster and more efficient public administration services. It improves the creation and implementation of public policies and helps the public sector to cope with conflicting requirements to provide more high quality services while using less resources. [16, 17]

According to Silcock (2001), "e-Government uses technology to increase availability and provide public services for the benefit of citizens, business partners and employees." [18]

In 2010, Spirakis, Spiraki and Nikolopoulos defined e-Government as follows: "Public administration electronisation is the use of information and communication technologies in government transformation, especially with the aim of improving accessibility, efficiency and accountability. It is based on the dissemination of information and the development of information policy. Electronic governance leads to an increase in citizens' participation, which affects the mechanisms of democracy. "[19]

The unification of the concept of electronization and the process of providing freely available information to the population is called e-Government. It is therefore an electronization of platforms for state information systems, whose information flows from 
the state sector to the public sector and vice versa. Online communication of e-Government takes place in five spheres:

- Government to Government $(\mathrm{G} 2 \mathrm{G})$ model is about online communication between governmental organizations, departments and agencies. The efficiency and effectiveness of processes is enhanced by the use of online communication and collaboration that enables the sharing of databases and resources, as well as the pooling of skills and competencies,

- Government to Employee (G2E) - is regarded by some authors as an internal part of $\mathrm{G} 2 \mathrm{G}$, others see it as a separate component of eGovernment. This is an online communication between public administarion and employees of institutions falling under public administration,

- Government to Citizen (G2C) model includes relationships between the government and citizens. These relationships can be represented, for example, by providing information on public administration. This model describes mainly the provision of public administration services to citizens,

- Government to Business (G2B) model includes relationships between the government and business,

- Government to Administration (G2A) - on-line communication between the public administration and the administration (EU Member State institutions and EU institutions). [20]

Analysis of individual spheres of open data, or to what extent the concept of Open data in Slovakia is implemented and used can be found in the global ranking of the Global Open Data Index. [21] According to the ranking, Slovakia ranked together with 26 countries at the top of the ranking. The following facts were considered:

- Availability without license restriction,

- Machine-readable information,

- Downloadable,

- Timeliness,

- Publicly available,

- Free of charge.

Individual surveys are carried out in the field of open data and their use and implementation. In Slovakia are well evaluated information datasets such as National Statistics, Procurement, Locations, less Government Budget, Company Register, National Law. National Maps, Air quality, Land Ownership, very poor Water Quality, Government Spending. Not all of these datasets have similar access and usage characteristics. For example, freely available national statistics are free of any restrictions or charges. This data includes information such as key national statistics on demographic and economic indicators such as Gross Domestic Product (GDP) or unemployment and population statistics. Similarly, procurement data is in the same position. [21]

\section{Results of the survey}

The primary research was conducted expert interviews. Experts work in the areas of contact with data, in particular with freely available data on the performance of public administration. They are therefore highly competent and oriented towards carrying out this research. The interviews were conducted with competent staff from areas such as human resources, human resources, marketing, IT.

All respondents again agreed on the common view that the electronization of state and public administration will streamline the process of document processing, saving costs, time and many other factors. Possible factors that could slow this process down are citizens' 
lack of awareness of the availability of these data categories, the interest to read available data, technology shortage, poor web design levels, and poor or no skill in the elderly or disabled. Within the web design we are talking about the so-called. the logical disintegration of information so that its sharing is effective for the final consumer of the data.

The state of electronization in Slovakia can be considered as innovative. Competent persons who come into contact with open data on a daily basis consider their sharing to the public as an effective process solution process. The study of the National Concept of Informatisation of Public Administration of the Slovak Republic speaks about citizens' satisfaction.

Of course, there is a need to improve the content and logical structure of the specific portals of the institutions that provide this data. It is also necessary to:

- Raising awareness among citizens and businesses - the process of raising awareness among people is the cornerstone of people's interest. This is an important aspect and, logically, the greater the number of citizens who are made aware of freely available public administration data, the greater the increase in the involvement of citizens in this process.

- Involvement of more citizens and businesses - an increase in citizens using public administration services would theoretically increase the speed of processing of individual processes, ie the time of processing and submitting (e-form) of the document. This is associated with cost savings in administration. This improvement could only occur if more citizens are aware of the existence of these types of data. Another and most important should be the skills of the population in browsing individual datasets.

- Improve the content of the institutions providing this data - diversify the content of this data or expand it. In this way, there could be an increase in interest in tracking open data (in each age category).

- Improve the logical structure of the portals - previous innovative solutions were not only more difficult to implement, but would require a certain amount of funding. This aspect involves a purely technological process of improving the logical information architecture of the site. These are web design practices associated with the process of effectively distributing page attributes so that the main goals of the page are maximized.

\section{Conclusion}

The present time brings new technologies. The digital economy also means changes in public administration in times of globalization. The electronization of public administration is one of the milestones in the development of technological processes, leading to the improvement of the population's life. So it's no longer just about integrating information within one institution or business. The concept of national disclosure and the provision of important information was developed. The Europe 2020 project is being implemented, but the process of e-government is ongoing worldwide.

World leaders in process digitization and data needs to be followed to improve quality, availability, etc. An important technological aspect is the compatibility or interoperability of computer systems - interoperability. Without this, there would be no massive dissemination of any information. In this respect, the arguments of exports on the provision of data by public administration institutions, as well as the use of this data by private enterprises, were also mentioned.

This paper was supported by project KEGA 043ZU-4/2019 and VEGA 1/0768/19. 


\section{References}

1. R. Štefko, R. Bačík, R. Fedorko, M. Oleárová, M.Rigelský, Analysis of consumer preferences related to the use of digital devices in the e-commerce dimension, Entrepreneurship and Sustainability, 7 (1), 25-33 (2019)

2. J. Veber, Digitalizace ekonomiky a společnosti. (Praha: Management Press, 2018)

3. Z. Stofkova, D. Hraskova, Digital skills in period of digital economy. Marketing Identity, Univ Ss Cyril \& Methodius Trnava, 417-425 (2017)

4. M. Moroz, The Level of Development of the Digital Economy in Poland and Selected European Countries: A Comparative Analysis, Foundations of Management, 9 (2017)

5. G. Karnitis, A. Virtmanis, E. Karnitis, Key Drivers of Digitalization; EU Context and Baltic Case, Baltic J. Modern Computing, 7, 1, 70-85 (2019)

6. S. Stofko, V. Soltes, Z. Stofkova, Options of using the integrated management system, Production management and engineering sciences, pp. 267-272 (2016)

7. I. Litvaj, O. Poniščiaková, Entrepreneurship and quality management, Entrepreneurship and Sustainability, 1(4), 204-209 (2014)

8. M. Dečman, The Analysis of E-Government Services Adoption and Use in Slovenian Information Society between 2014 and 2017, Central European Public Administration Review, 16, 2, 193-215 (2018)

9. L. Floridi, Information - A Very Short Introduction (Oxford University Press, 2010)

10. Oxford Dictionaries, Data definition (2012)

11. A. Halonen, Being Open About Data Analysis of the UK open data policies and applicability of open data (The Finnish Institute in London, 2017)

12. A. Brandusescu, C. Iglesias, K. Robinson, The World Wide Web Foundation- Open Data Barometer 4th Edition - Global Report (2017)

13. V. Soltes et al., Education in information society, INTED Proceedings, pp. 4418-4424 (2016)

14. S. Vasudevan, How User Insights can Help Attract and Retain Citizens in EGovernment Services (Silver Touch Technologies Inc., 2014)

15. UNO: eGovernment Survey 2016 (New York: UNO 2016)

16. V. Lidinský, eGovernment bezpečně. (Praha: Grada, 2008)

17. J. Kubas, Z.Stofkova, J. Misik, Impact of fiscal decentralization of public administration. CBU International conference proceedings, 5, pp. 242-246 (2017)

18. R. Silcock, What is E-government, Parliamentary affairs, 54, 1, 88-101 (2001)

19. G. Spirakis, CH. Spirakis, K. Nikolopoulos, The impact of electronic government on democracy: E-democracy through e-participation, Electronic Government, International Journal., 7, 1, 75-88, (2010)

20. Z. Fang, E-Government in Digital Era: Concept, Practice, and Development, International Journal of the Computer, the Internet and Management, 10, 2, 1-22 (2002)

21. Open Knowledge Foundation, Global Open Data Index, Slovakia (2016) 